\title{
DeTERMINAÇÃo DA QUANTIDADE DE AREIA NO ESGOTO SANITÁRIO: METODOLOGIA E ESTUDO DE CASO
}

\section{DETERMINATION OF GRIT QUANTITY IN WASTEWATER: METHODOLOGY AND CASE STUDY}

\begin{abstract}
Gustavo Silva do Prado
Engenheiro Sênior da Concremat Engenharia e Tecnologia S/A. Doutor em Engenharia Hidráulica e Sanitária pelo Departamento de Hidráulica e Saneamento da Escola de Engenharia de São Carlos da Universidade de São Paulo
\end{abstract}

\author{
JOSÉ ROBERTo CAMPOS \\ Professor Titular do Departamento de Hidráulica e Saneamento da Escola de Engenharia de São Carlos da \\ Universidade de São Paulo
}

Recebido: 01/08/07 Aceito: 16/07/08

\section{RESUMO}

Apesar de os desarenadores serem largamente utilizados, há mais de um século, como uma das unidades que compõem o tratamento preliminar de estações de tratamento de esgoto (ETEs), pouco se sabe a respeito de suas eficiências de remoção devido à total carência de métodos analíticos padronizados para determinação da concentração de areia presente no esgoto sanitário. O presente artigo apresenta um método original para determinação da concentração de areia no esgoto, baseado no emprego de procedimentos amplamente conhecidos, como: sedimentação em cones Imhoff, oxidação com peróxido de hidrogênio, enxágües sucessivos, calcinação e pesagem em balança analítica. A aplicação do método desenvolvido demonstrou que a concentração de areia no esgoto sanitário afluente da ETE Jardim das Flores (Rio Claro, SP) apresenta grande variabilidade com picos de até $200 \mathrm{mg} / \mathrm{l}$ e que a concentração média de areia encontra-se entre $20 \mathrm{mg} / \mathrm{l}$ e $73 \mathrm{mg} / \mathrm{l}$.

PALAVRAS-CHAVES: Desarenadores, caixas de areia, concentração de areia, método de determinação, avaliação estatística, ETE Jardim das Flores

\begin{abstract}
Although degritters have been largely used, for more than a century, as preliminary treatment units of wastewater treatment plants (WWTP), their removal efficiency is yet poorly known due to the lack of standardized analytical methods to determine wastewater grit concentration. This paper brings up this subject and presents an original method to determine wastewater grit concentration based on use of well-known procedures, such as: Imhoff cone sedimentation, hydrogen peroxide oxidation, sequential rinse, calcination and analytical balance weighing. The application of the developed method demonstrated that grit concentration in the influent of WWTP Jardim das Flores varies significantly, with peak concentration of about $200 \mathrm{mg} / \mathrm{l}$, and that the mean grit concentration seems to be among $20 \mathrm{mg} / \mathrm{l}$ and $73 \mathrm{mg} / \mathrm{l}$.
\end{abstract}

KEYWORDS: Degritters, grit chambers, grit concentration, determination method, statistical evaluation, WWTP Jardim das Flores.

\section{INTRODUÇÃO}

O emprego de desarenadores como unidades de operação que compóem a etapa de tratamento preliminar de estaçóes de tratamento de esgoto (ETEs) é prática comum entre projetistas há mais de um século (Camp, 1942). Todavia, ainda hoje pouco se sabe a respeito da eficiência dessas unidades. Mesmo textos consagrados, como Metcalf \& Eddy (2003), pouco acrescentam a respeito do tema, porquanto, segundo seus autores é muito difícil interpretar dados de eficiência de remoção de desarenadores devido à escassez destas informaçóes e ao fato dos materiais que estas unidades removem serem apenas grosseiramente caracterizados.
No Brasil, os desarenadores são comumente denominados "caixas de areia”. Ambos os nomes podem levar a conclusōes errôneas acerca do material que esse tipo unidade remove, pois a palavra desarenador etimologicamente significa separador de areia. Todavia o material removido pelos desarenadores compreende uma infinidade de partículas sólidas de diversos tamanhos e tipos, como por exemplo: areia, silte, pó de carvão, cinzas, pó de café, sementes de frutas, fragmentos de ossos e de cascas de ovos etc. (Camp, 1942). Pode-se afirmar que os desarenadores são unidades de operação unitária responsáveis pela remoção de partículas discretas com elevada velocidade relativa de sedimentação.
No entanto, conhecer quais tipos de partículas são removidas em um desarenador não é suficiente para se medir sua eficiência; faz-se necessário, também, saber em quais quantidades esses materiais são encontrados, tanto no afluente (esgoto bruto peneirado ou gradeado), quanto no efluente da unidade. Essa tarefa, diferentemente de apenas inventariar constituintes, não é fácil, dada à heterogeneidade e à variabilidade dos sólidos que os desarenadores podem remover. Não obstante, segundo Camp (1942) "a experiência tem demonstrado que se um desarenador for capaz de remover todos os grãos de areia maiores ou iguais a $0,2 \mathrm{~mm}$, ele removerá a maior parte do material causador de problemas em 
ETEs”. Essa citação é quase tão antiga quanto os próprios desarenadores e como conseqüência de sua aceitação ao longo dos anos a tradição de seu uso acabou tacitamente convencionando a quantidade de areia como "parâmetro" de controle dessas unidades e $0,2 \mathrm{~mm}$ $(200 \mu \mathrm{m})$ como tamanho das menores partículas que devem ser removidas por um desarenador.

Apesar de o "parâmetro" quantidade de areia e o tamanho limite de $0,2 \mathrm{~mm}$ serem mundialmente aceitos como forma de se avaliar a eficiência de remoção de unidades de desarenação, ainda não existe tal consenso acerca de qual técnica analítica deve ser empregada para medi-los. Gardner e Deamer (1996) acenaram para o fato de que até 1996 não existiam métodos de análise padronizados nem para determinação da massa, nem para determinação da distribuição granulométrica da areia presente em amostras de esgoto, mas o surpreendente é que passados 10 anos tais métodos ainda inexistem.

Gardner e Deamer (1996) alertam sobre um sério problema decorrente da falta de métodos de análise padronizados para determinação da quantidade (massa ou concentração) e da distribuição granulométrica da areia presente no esgoto sanitário. Segundo esses autores, esta carência metodológica dificulta negociaçôes entre clientes (municipalidades, companhias de saneamento e projetistas) e empresas que projetam e fornecem desarenadores, pois nem os fornecedores podem comprovar a eficiência de suas unidades, nem os clientes podem verificar se as unidades fornecidas atendem às especificaçôes de projeto.

No intuito de trazer à tona um tema importante que há tempos permanece pouco valorizado, o presente trabalho apresenta uma metodologia de análise para determinação da quantidade de areia presente no esgoto sanitário e os resultados obtidos de sua aplicação em um estudo acerca das concentraçōes de areia carreadas pelo esgoto sanitário afluente da ETE Jardim das Flores, localizada no município de Rio Claro, SP.

\section{MATERIAL E MÉTODOS}

\section{Considerações iniciais}

O método de determinação de concentração de areia presente no esgo- to sanitário originou-se de um método no qual a oxidação com peróxido de hidrogênio é utilizada para separar areia da matéria orgânica em amostras de lodo primário. Os autores deste artigo simplesmente adaptaram e incrementaram os procedimentos desse método, de forma a possibilitar a sua utilização para separar a areia da matéria orgânica em amostras muito mais diluídas.

Dos percalços encontrados para proposição do método de determinação da concentração de areia, três merecem destaque especial: o primeiro deriva da baixa concentração relativa de areia presente no esgoto proveniente de sistemas de coleta do tipo separador absoluto; o segundo tem origem na presença de partículas orgânicas nas amostras e o terceiro decorre da dificuldade de se conseguir amostras de esgoto bruto que sejam representativas.

Problemas referentes à determinação de compostos, contaminantes etc., que apresentam baixa concentração no esgoto sanitário são corriqueiros na rotina de qualquer laboratório de análises e podem ser atenuados com o esmero do experimentador ao realizar cada procedimento descrito na metodologia, no entanto outras medidas podem ser adotadas, como por exemplo, o uso de maiores volumes de amostra.

A presença de material orgânico, tanto aderido aos grãos de areia como suspenso no meio líquido, foi o maior obstáculo a ser transposto. Este problema, a princípio aparenta ter solução trivial, pois se poderia calcinar a amostra de esgoto em mufla à $550^{\circ} \mathrm{C}$, como é feito nas determinações de sólidos voláteis (SV) e sólidos fixos (SF). Porém esse procedimento não elimina por completo o material orgânico, isto é, os resíduos resultantes de sua queima não desaparecem, apenas tornam-se partículas muito pequenas indistinguíveis em meio aos grãos de areia (Gardner e Deamer, 1996). A solução para esse impasse foi obtida concentrando-se os sólidos das amostras, depois oxidando o material orgânico com peróxido de hidrogênio e por fim, dentro do possível, separando ou eliminando os resíduos da oxidação da matéria orgânica presente por meio de lavagens sucessivas da amostra com água destilada.

$\mathrm{O}$ terceiro problema que merece destaque refere-se à escolha de procedimento de amostragem adequado, certamente o "gargalo" do método. Neste caso, deve-se entender como adequado aquele procedimento pelo qual seja possível coletar amostras representativas, mas que acima de tudo ofereça a praticidade necessária.

Os grãos de areia geralmente são as partículas mais densas entre aquelas usualmente encontradas no esgoto sanitário bruto, por conseguinte tendem a concentrar-se no fundo de canais e tubulaçôes por onde escoa o esgoto. Esta peculiaridade acarreta sérias dificuldades ao processo de amostragem, deste modo, a escolha do processo adequado dependerá muito da criatividade do experimentador em improvisar soluçóes práticas que se adéqüem aos problemas de cada ETE.

Não existe regra clara em relação ao volume de esgoto que deve ser coletado, porém é importante lembrar que a concentração de areia no esgoto sanitário, em regra, é relativamente baixa, conseqüentemente, quanto maior o volume de amostra coletada, menor será o erro amostral do ensaio. Quanto ao tipo de amostragem a ser escolhida, isso dependerá do tipo de análise que se pretende fazer. Podem-se realizar perfis de monitoramento 24 horas com amostragens horárias, para acompanhar a variação da concentração de areia no esgoto, ou coletar grande número de amostras pontuais à montante e à jusante de desarenadores, para avaliar a eficiência de remoção dessas unidades ou, ainda, coletar amostras compostas, para ser determinada a concentração média diária de areia no esgoto bruto.

\section{Arranjo experimental}

$\mathrm{Na}$ presente pesquisa, as amostras de esgoto bruto foram coletadas da estação elevatória da ETE Jardim das Flores (vazão média bombeada de aproximadamente $324 \mathrm{~m}^{3} / \mathrm{h}$ ) localizada no município de Rio Claro, SP. Devido à configuração espacial da chegada do esgoto bruto e ao arranjo experimental da pesquisa, optou-se pelo uso de bomba submersível, posicionada dentro do poço de sucção da elevatória, junto ao anteparo que o separa do canal de chegada de esgoto. A escolha deste local é justificável por ser o arranjo experimental que menos interferiria na operação da estação elevatória e consequentemente da ETE. Também merece destaque o fato de a bomba submersível não ter sido posicionada junto ao fundo do poço de sucção da elevatória e sim junto à parede lateral 
do anteparo que o separa do canal de chegada do esgoto.

A bomba submersível era empregada para alimentar um separador hidrodinâmico por vórtice (SHV), tema central do trabalho de pesquisa que originou o presente artigo (Prado, 2006). Na entrada da unidade foi instalada uma válvula de esfera de $50 \mathrm{~mm}$, por onde foram coletadas todas as amostras de esgoto bruto utilizadas na pesquisa.

As amostras foram coletadas em garrafas plásticas de um litro, de hora em hora; geralmente das $9 \mathrm{~h} 00 \mathrm{~min}$ até as $13 \mathrm{~h} 30 \mathrm{~min}$ ou das $14 \mathrm{~h} 00 \mathrm{~min}$ até as $17 \mathrm{~h} 30 \mathrm{~min}$. Depois de coletadas, as amostras eram conservadas em refrigerador até o momento das determinações em laboratório.

\section{Materiais e equipamentos}

Os materiais e equipamentos empregados na execução dos ensaios de determinação da concentração $(\mathrm{mg} / \mathrm{l})$ de areia presente no esgoto sanitário foram:

- Três cones Imhoff com adaptação para coleta de fundo;

- Um suporte para Cones Imhoff;

- Bastonete de vidro para promover agitação; coleta;

- Três béqueres de $100 \mathrm{ml}$ para

- Béquer de $250 \mathrm{ml}$ ou $500 \mathrm{ml}$ para descarte;

- Duas pipetas de $20 \mathrm{ml}$ ou $10 \mathrm{ml}$;

- Doze tubos Falcon de $15 \mathrm{ml}$ ou mais;

- Pisseta com água destilada;

- Peneira de plástico;

- Garrafas de um litro para coleta de amostras;

- Peróxido de hidrogênio $\left(\mathrm{H}_{2} \mathrm{O}_{2}\right)$ (solução 35\%);

- Cronômetro digital; $50 \mathrm{ml}$

- Doze cápsulas de porcelana de

- Agitador elétrico de tubos de ensaio (opcional);

- Centrífuga;

- Balança analítica;

- Mufla que opere a 550 C.

\section{Procedimentos de análise}

Os procedimentos adotados para execução dos ensaios de determinação da quantidade de areia foram:

- Colocar os três cones Imhoff em seu suporte e posicionar os três béqueres de $100 \mathrm{ml}$ sob cada um dos cones;

- Verter o conteúdo das garrafas nos cones Imhoff (uma garrafa por cone), usando a peneira de plástico para evitar que sólidos grosseiros presentes na amostra adentrem os cones;

- Com a pisseta, enxaguar as garrafas onde estavam as amostras de esgoto, de modo que todas as partículas que eventualmente ainda permaneçam dentro delas sejam carreadas para dentro dos cones. Cuidado especial deve ser dispensado nesta etapa, pois os grãos de areia tendem a permanecer no fundo das garrafas;

- Disparar o cronômetro digital;

- Após 20 min, com ajuda de bastonete de vidro, delicadamente ressuspender as partículas que permanecem junto às paredes dos cones Imhoff;

- Após $30 \mathrm{~min}$, coletar apenas os sólidos que se concentraram no fundo dos cones Imhoff nos béqueres posicionados sob cada cone;

- Verter o conteúdo de cada béquer de $100 \mathrm{ml}$ em um tubo Falcon de $15 \mathrm{ml}$;

- Com a pisseta, enxaguar cada béquer de modo que partículas eventualmente retidas em seus interiores sejam arrastadas para dentro dos tubos Falcon;

- Centrifugar os tubos Falcon por 30 segundos;

- Descartar sobrenadante de cada tubo Falcon;

- Com a pipeta, dosar aproximadamente $10 \mathrm{ml}$ de peróxido de hidrogênio $\left(\mathrm{H}_{2} \mathrm{O}_{2}\right)$ em cada tubo Falcon;

- Com o agitador elétrico agitar os tubos Falcon por alguns segundos para que os sólidos que se encontram no fundo dos tubos sejam misturados com o peróxido de hidrogênio;

- Deixar os tubos Falcon em repouso por alguns segundos para que a areia mais densa sedimente e se concentre no fundo dos tubos, enquanto a matéria orgânica oxidada, juntamente com partículas muito pequenas flotem devido às micro-bolhas formadas pela dissociação do peróxido de hidrogênio;

- Descartar a camada de escuma formada no tubo Falcon em béquer de $500 \mathrm{ml}$ (esse procedimento deve ser realizado tubo por tubo, isso é não se deve descartar o conteúdo de dois tubos em um mesmo béquer);

- Com a pipeta, cuidadosamente remover o líquido sobrenadante, tomando cuidado para não pipetar a areia depositada no fundo do tubo Falcon, e descartá-lo no mesmo béquer de $500 \mathrm{ml}$ no qual se encontra a escuma; - Com a pisseta, completar o tubo Falcon com água destilada;

- Repetir os dois procedimentos anteriores até que a água que se encontra dentro do tubo Falcon fique límpida ("visualmente clarificada"). Tal procedimento é muito importante, pois a areia acumulada no fundo do tubo deve ser lavada para que sejam eliminados quaisquer resquícios de matéria orgânica aderida aos grãos;

- Devido ao fato de parte das partículas (predominantemente as muito finas) que se encontram na amostra serem descartadas juntamente com a escuma no béquer de $500 \mathrm{ml}$, faz-se necessário promover a recuperação desse material. Para isso deve-se cuidadosamente verter o sobrenadante do béquer em outro recipiente, tomando cuidado para não perder as pequenas partículas que se acumulam no seu fundo.

- Com a pisseta, enxaguar o material que permanece no béquer;

- Com uma pipeta, cuidadosamente remover o líquido sobrenadante, tomando cuidado para não pipetar as pequenas partículas que se encontram no fundo do béquer;

- Repetir os dois procedimentos anteriores até que o líquido que se encontra dentro do béquer fique límpido;

- Pipetar o líquido em excesso e retornar as partículas contidas no béquer para dentro do tubo Falcon de origem deste material;

- Com a pisseta, enxaguar o béquer de $500 \mathrm{ml}$, de modo que, partículas, que eventualmente fiquem retidas na sua parede e fundo, sejam enxaguadas para dentro do tubo Falcon;

- Verter o conteúdo de cada tubo Falcon em cápsulas de porcelana de $50 \mathrm{ml}$ previamente preparadas (calcinadas à $550^{\circ} \mathrm{C}$ em mufla) e pesadas $\left(\mathrm{P}_{0}\right)$;

- Calcinar as cápsulas de porcelana em mufla à $550^{\circ} \mathrm{C}$, para ser eliminado qualquer material volátil que ainda permaneça aderido aos grãos de areia;

- Remover as cápsulas da mufla e deixá-las esfriar em dessecador, depois pesá-las para obter $\mathrm{P}_{1}$;

- Usar a Equação 1 para calcular a concentração de areia da amostra;

$\mathrm{C}_{\mathrm{AR}}=\frac{\mathrm{P}_{1}-\mathrm{P}_{0} \mathrm{~h}}{\mathrm{~V}_{\mathrm{am}}}$

Em que:

$\mathrm{C}_{\mathrm{AR}}$ : Concentração de areia na amostra $(\mathrm{mg} / \mathrm{l})$; 
$\mathrm{P}_{0}$ e $\mathrm{P}_{1}$ : Pesos provenientes das pesagens das cápsulas $(\mathrm{mg})$;

$\mathrm{V}_{\mathrm{am}}$ : Volume de amostra utilizada no ensaio (l).

\section{RESULTADOS E DISCUSSÃO}

\section{Análise das concentrações médias de areia no esgoto sanitário}

Para determinar a concentração média de areia encontrada nas 34 amostras de esgoto sanitário afluente da estação de tratamento de esgoto (ETE) Jardim das Flores, as quais foram coletadas em 11 dias diferentes, entre $17 / 8 / 2005$ e $21 / 11 / 2005$, das $9 \mathrm{~h} 30 \mathrm{~min}$ até $17 \mathrm{~h} 30 \mathrm{~min}$, fez-se uso de análise estatística.
Primeiramente, os resultados obtidos foram plotados nos gráficos das Figuras 1 e 2, os quais apresentam, respectivamente, o histograma de freqüências relativas e o gráfico de distribuição de freqüências relativas acumuladas.

Pode-se observar na Figura 1 que o intervalo com o maior valor de freqüência (moda) vai de $30 \mathrm{mg} / \mathrm{l}$ a $45 \mathrm{mg} / \mathrm{l}$ e pelo gráfico da Figura 2 é possível constatar que a mediana da distribuição de freqüências das 34 amostras é aproximadamente $40 \mathrm{mg} / \mathrm{l}$. Por conseguinte, conclui-se da análise desses gráficos que uma boa estimativa para a concentração média de areia nas 34 amostras de esgoto, coletadas junto à estação elevatória da ETE Jardim das Flores, está entre $30 \mathrm{mg} / \mathrm{l}$ e $45 \mathrm{mg} / \mathrm{l}$.

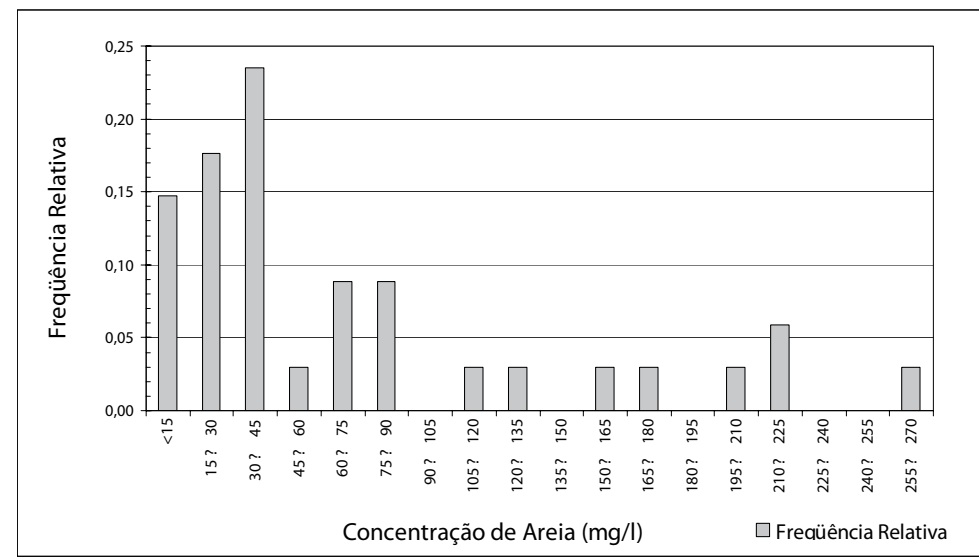

Figura I - Histograma de freqüências relativas, obtido a partir de 34 amostras de esgoto sanitário, coletadas junto à estação elevatória localizada nas proximidades da ETE Jardim das Flores da cidade de Rio Claro, SP, entre I 7/8/2005 e 2 I/I I/2005, das 9 h30min até I 7 h30min

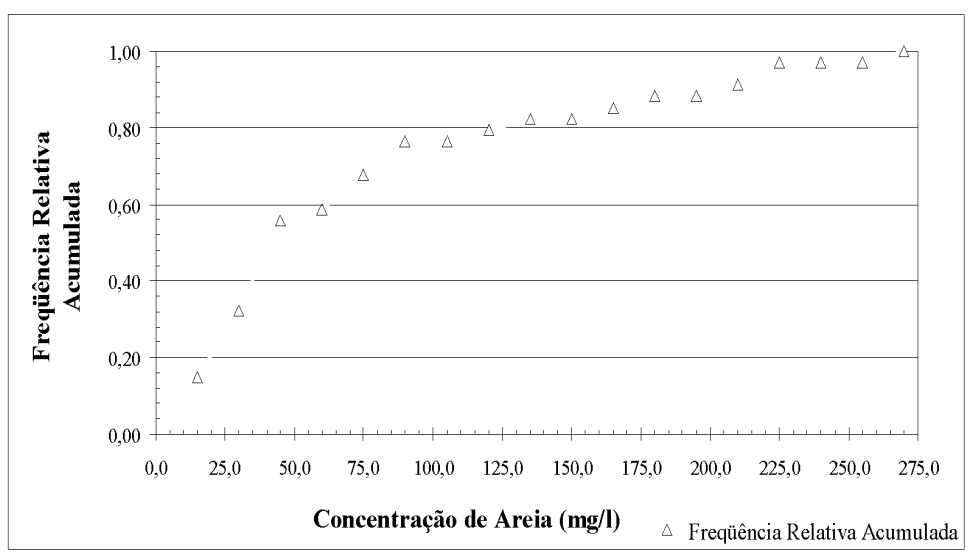

Figura 2 - Distribuição de freqüências relativas acumuladas, obtido a partir de 34 amostras de esgoto sanitário, coletadas junto à estação elevatória localizada nas proximidades da ETE Jardim das Flores da cidade de Rio Claro, SP, entre I7/8/2005 e 2 I/I I/2005, das 9 h30min até I 7h30min

Todavia, tais concentrações são valores médios amostrais, pois se referem somente ao conjunto de dados analisados. Para se obter valores médios de concentração de areia que possam ser extrapolados para quaisquer amostras coletadas na estação elevatória da ETE Jardim das Flores (i.e. valores médios populacionais de concentração de areia) é necessário certo aprofundamento na análise estatística, observando as características da distribuição dos dados amostrais, ou seja, das concentraçôes de areia obtidas.

Uma forma de representar a curva de distribuição de concentrações de areia encontradas nas 34 amostras de esgoto sanitário é o gráfico da Figura 3. Nele pode ser observado o formato da curva de distribuição das concentrações de duas maneiras, uma pela própria distribuição dos dados e outra por um tipo de gráfico chamado box-plot.

Observa-se no gráfico da Figura 3 certa assimetria na distribuição das concentraçōes de areia. Este fato demonstra que os 34 dados amostrais analisados não se distribuem normalmente em torno de uma média. No entanto, segundo Barros Neto et al (2002), em situaçôes como esta, considerando que a concentração de areia no esgoto é uma variável aleatória, pode-se fazer uso de um dos teoremas fundamentais da Estatística o Teorema do Limite Central, o qual assevera que "se a flutuação total de uma certa variável aleatória for o resultado da soma das flutuaçôes de muitas variáveis independentes e de importância mais ou menos iguais, a sua distribuição tenderá para a normalidade, não importa qual seja a distribuição das variáveis individuais (Barros Neto et al, 2002)”.

Assumindo que a concentração de areia no esgoto sanitário é uma variável aleatória, e que pelo Teorema do Limite Central a distribuição das concentrações médias de areia no esgoto para uma amostra grande o bastante se distribui normalmente, foram calculados dois intervalos de confiança, um baseado na média aritmética e outro baseado na média geométrica das concentraçôes de areia encontradas nas 34 amostras de esgoto sanitário. Os dois intervalos de confiança (IC) foram calculados usando a distribuição t-Student (variâncias populacionais desconhecidas) com nível de significância de $95 \%$, e são apresentados na Tabela 1 , juntamente com outros parâmetros estatísticos do conjunto amostral. 


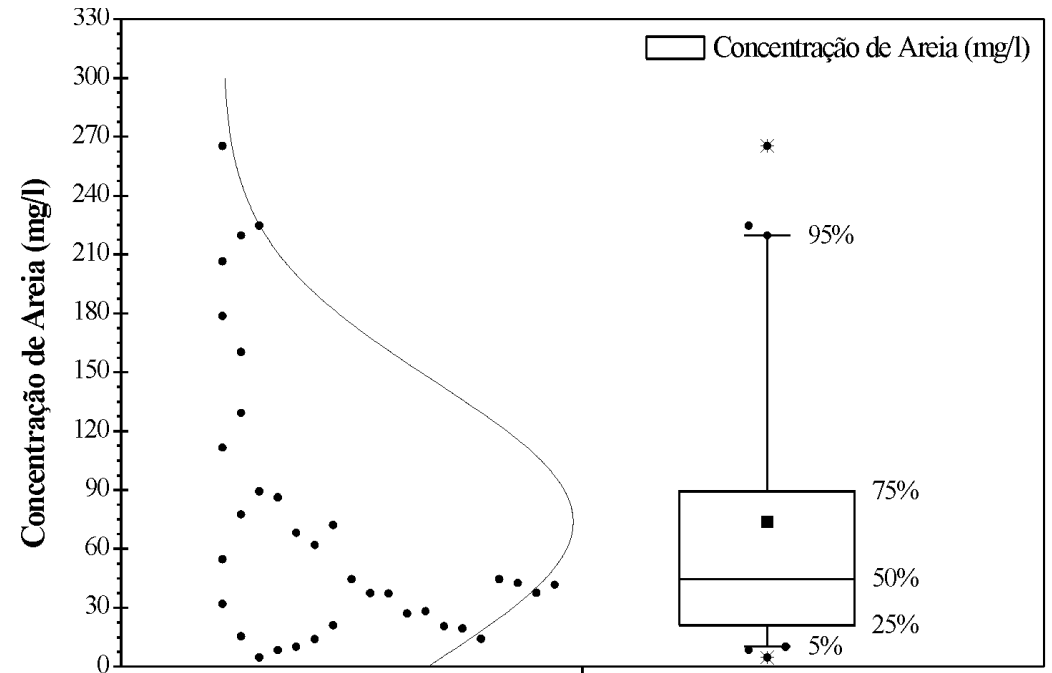

Esg.Bruto

Figura 3 - Gráfico tipo box-plot e curva de distribuição das concentrações de areia obtidas a partir de 34 amostras de esgoto sanitário, coletadas junto à estação elevatória localizada nas proximidades da ETE Jardim das Flores da cidade de Rio Claro, SP. (घ) Média aritmética dos dados; (*) Valores máximos e mínimos observados

Tabela I - Intervalos de confiança baseados nas médias aritmética e geométrica com níveis de significância de 95\%, e parâmetros estatísticos da distribuição de concentrações de areia

\begin{tabular}{cc}
\multicolumn{2}{c}{ Concentração de areia $(\mathrm{mg} / \mathrm{l})$} \\
\hline Média geométrica & 47 \\
Desvio padrão & 76,5 \\
$\mathrm{IC}\left(\mu_{\mathrm{g}} ; 95 \%\right)=[20 \mathrm{mg} / \mathrm{l} ; 73 \mathrm{mg} / \mathrm{l}]$ & \\
Média aritmética & 74 \\
Desvio padrão & 71,4 \\
$\operatorname{IC}\left(\mu_{\mathrm{a}} ; 95 \%\right)=[50 \mathrm{mg} / \mathrm{l} ; 100 \mathrm{mg} / \mathrm{l}]$ & \\
Mediana & 44 \\
Mínimo & 5 \\
Máximo & 265 \\
Número de amostras & 34 \\
\hline
\end{tabular}

A observação dos dados dispostos na Tabela 1 permite concluir que a concentração de areia presente no esgoto sanitário afluente da ETE Jardim das Flores apresenta grande variabilidade, fato corroborado pela amplitude dos ICs e pela diferença entres as concentraçôes máxima $(265 \mathrm{mg} / \mathrm{l})$ e mínima $(5 \mathrm{mg} /)$ de areia observadas.

A análise da distribuição dos valores de concentração mostra que o valor da média geométrica (47 mg/l), por ser menos influenciado pelos valores extremos, é mais próximo ao valor da mediana do conjunto de dados (44 mg/l); consequentemente, ele pa- rece representar com mais fidelidade o valor médio da distribuição de concentraçôes de areia; por isso, o intervalo de confiança calculado a partir dele pode ser considerado como boa estimativa, isto é, a concentração média de areia no esgoto sanitário estudado tem $95 \%$ de chance de estar entre $20 \mathrm{mg} / \mathrm{l} \mathrm{e} 73 \mathrm{mg} / \mathrm{l}$.

Entretanto, quando se leva em consideração o emprego desses valores médios de concentração para o projeto de sistemas de remoção, lavagem e disposição final da areia presente no esgoto sanitário, a utilização de valores conservadores é recomendável. Deste modo, aconselha-se a adoção de IC calculado a partir de média aritmética como representação da concentração média de areia, a qual, para o esgoto sanitário estudado, com 95\% de significância, está entre $50 \mathrm{mg} / \mathrm{l}$ e $100 \mathrm{mg} / \mathrm{l}$.

\section{Análise da variabilidade das concentraçóes de areia no esgoto sanitário}

Como já mencionado neste texto, os valores de desvio padrão, a amplitude dos ICs calculados e a significativa diferença entre as concentrações mínima e máxima encontradas demonstram a grande variabilidade do valor da concentração de areia do esgoto sanitário afluente da ETE Jardim das Flores. No entanto, tais dados não permitem que essa variabilidade seja visualizada. Para que isso fosse possível, foi analisado um conjunto de dados composto por 24 valores de concentração de areia obtidos de amostras coletadas entre 6/10/2005 e 21/11/2005, das $10 \mathrm{~h} 30 \mathrm{~min}$ às $17 \mathrm{~h} 30 \mathrm{~min}$.

A Figura 4 mostra um histograma construído a partir desses valores; nele pode-se observar que a variabilidade dos valores de concentração é verificada não somente ao longo do dia, como também para uma mesma hora. Na Figura 5 foi plotado histograma com as médias aritméticas e geométricas calculadas para cada um dos horários estudados. Mais uma vez, observam-se diferenças significativas entre os valores de médias aritméticas e geométricas, principalmente às $11 \mathrm{~h} 30 \mathrm{~min}$ e às $16 \mathrm{~h} 30 \mathrm{~min}$, quando é grande a diferença entre os menores e os maiores valores de concentração de areia.

Em nenhuma das duas figuras nota-se algum tipo de padrão na variabilidade horária da concentração de areia presente no esgoto sanitário afluente da ETE Jardim das Flores; por isso nada pode ser concluído, além de que a concentração de areia pode apresentar variaçôes significativas tanto para um mesmo horário como ao longo de um dia.

Ainda analisando a variação horária da concentração de areia no esgoto, decidiu-se verificar a existência de diferenças entre as concentraçóes médias (populacionais) de areia em dois períodos: Período $\boldsymbol{1}$ das 9 h30min às 13 h30min e Período 2 das 13 h30min às $17 \mathrm{~h} 30 \mathrm{~min}$. Para isso, foram utilizados 32 valores de concentração de areia obtidos de amostras de esgoto coletadas entre 6/10/2005 e 21/11/2005, das $9 \mathrm{~h} 30 \mathrm{~min}$ às $17 \mathrm{~h} 30 \mathrm{~min}$. 


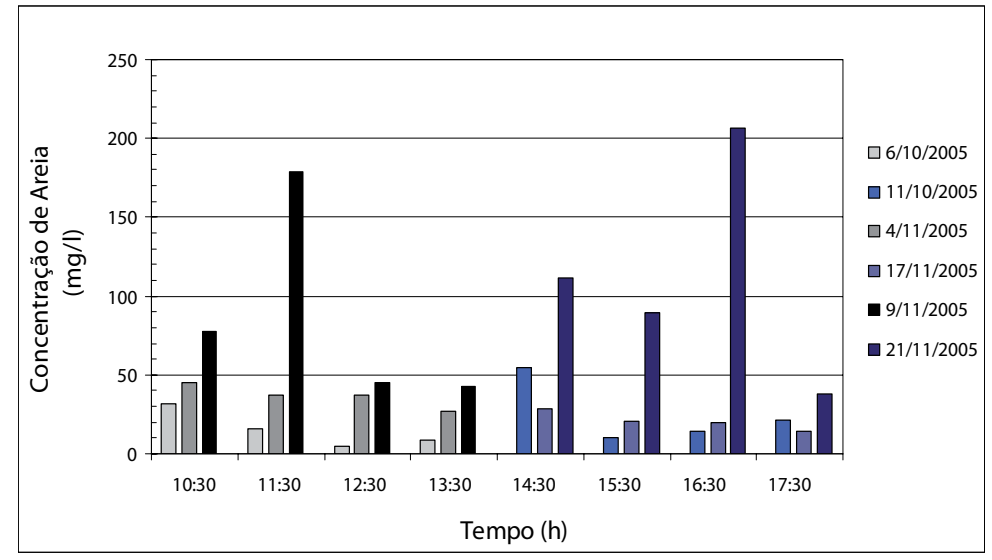

Figura 4 - Histograma de concentrações de areia construído a partir de 24 amostras de esgoto sanitário, coletadas junto à estação elevatória localizada nas proximidades da ETE Jardim das Flores da cidade de Rio Claro, SP, entre 6/9/2005 e $2 \mathrm{I} / \mathrm{I} / \mathrm{I} 2005$, das IOh30min até I 7h30min

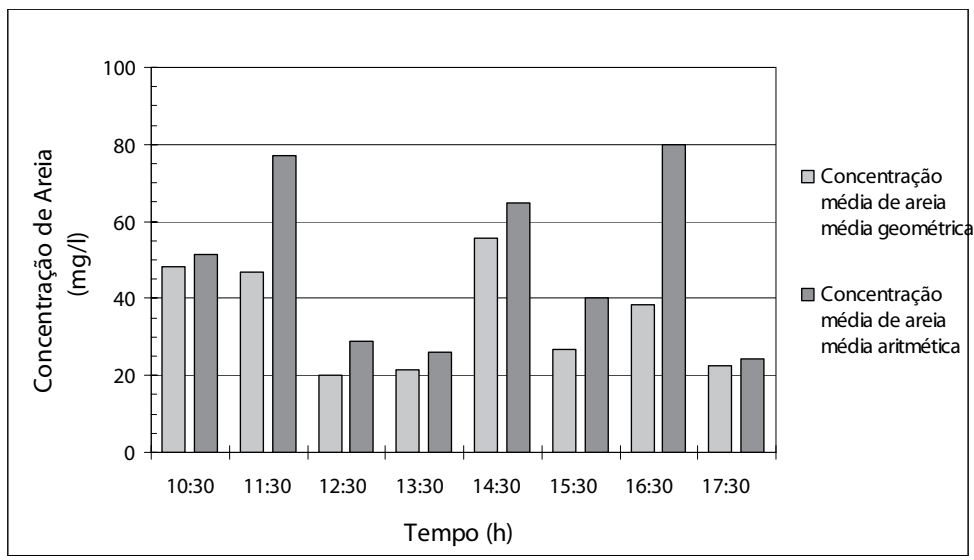

Figura 5 - Histograma de concentrações médias (geométrica e aritmética) de areia construído a partir de 24 amostras de esgoto sanitário, coletadas junto à estação elevatória localizada nas proximidades da ETE Jardim das Flores da cidade de Rio Claro, SP, entre 6/9/2005 e 2 I/I I/2005, das $10 \mathrm{~h} 30 \mathrm{~min}$ até $17 \mathrm{~h} 30 \mathrm{~min}$

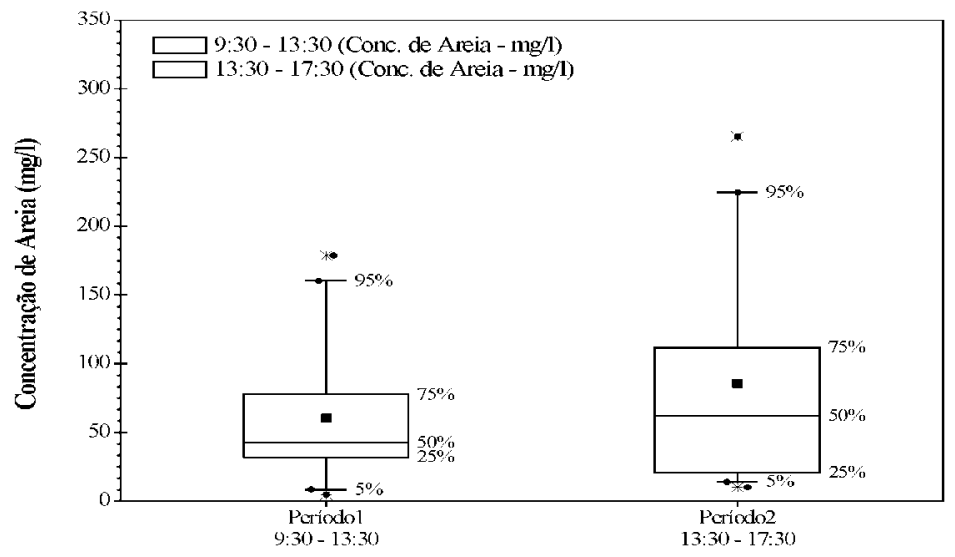

Figura 6 - Gráfico tipo box-plot das distribuições de concentração de areia para os dois períodos estudados, construído a partir de 32 amostras de esgoto sanitário, coletadas junto à estação elevatória localizada nas proximidades da ETE Jardim das Flores da cidade de Rio Claro, SP, entre 6/8/2005 e 2 I/I I/2005, das 9h30min até I 7h30min. (a a) Médias aritméticas dos dados; (* *) Valores máximos e mínimos
A Figura 6 mostra um gráfico do tipo box-plot com a distribuição de concentrações de areia dos dois períodos estudados. O gráfico permite que se observe pequena diferença entre as médias aritméticas amostrais dos dois períodos, porém para verificar se tal diferença é significativa e se faz presente entre as médias populacionais de concentração de areia foi empregada uma ferramenta estatística chamada teste de hipóteses.

Admitiu-se que as amostras dos dois períodos eram aleatórias, independentes e com variâncias desconhecidas e diferentes. O teste de hipóteses foi realizado utilizando umas das ferramentas de análise de dados do Microsoft Excel - o Teste- $\mathrm{t}$ - e seus resultados podem ser observados na Tabela 2 .

Como pode-se observar na Tabela 2, apesar das médias amostrais das concentraçōes serem diferentes, o Teste-t não verificou existência de diferença significativa entre as médias populacionais dos dois períodos estudados, pois $\mathrm{t}_{\mathrm{obs}}$ está fora da regiāo crítica de não aceitação da hipótese nula, ou seja, médias populacionais iguais. Logo, pode-se concluir que as concentrações médias de areia presentes no esgoto sanitário não diferiram significativamente nos dois períodos estudados.

\section{Extrapolação dos resultados experimentais}

A carência de dados acerca de quantidade de areia no esgoto sanitário impede a comparação dos resultados obtidos nesta pesquisa com valores encontrados em outras localidades. Contudo, a determinação de intervalo de confiança (IC) para concentração média de areia no esgoto sanitário entre $50 \mathrm{mg} / \mathrm{l}$ e $100 \mathrm{mg} / \mathrm{l}$ demonstra que o projeto de sistemas de desarenação de ETEs deve ser realizado com bastante critério pois, caso tais quantidades de areia não sejam devidamente removidas, seu acúmulo nas demais unidades das ETEs ocasionará sérios problemas operacionais à mesmas.

Para exemplificar a dimensão desse problema, pode-se fazer um mero exercício de raciocínio com os dados dessa pesquisa. Admitindo que uma ETE atenda população de 100.000 habitantes e adotando: 180 l/hab.dia, coeficiente de retorno de 0,8 e concentração média de areia no esgoto sanitário de $50 \mathrm{mg} / \mathrm{l}$; obtém-se com estes dados um total de $721 \mathrm{~kg}$ de areia seca por 
Tabela 2 - Dados estatísticos usados para a realização do teste de hipótese da média populacional de concentrações de areia dos dois períodos estudados, considerando amostras independentes com variâncias desconhecidas e diferentes

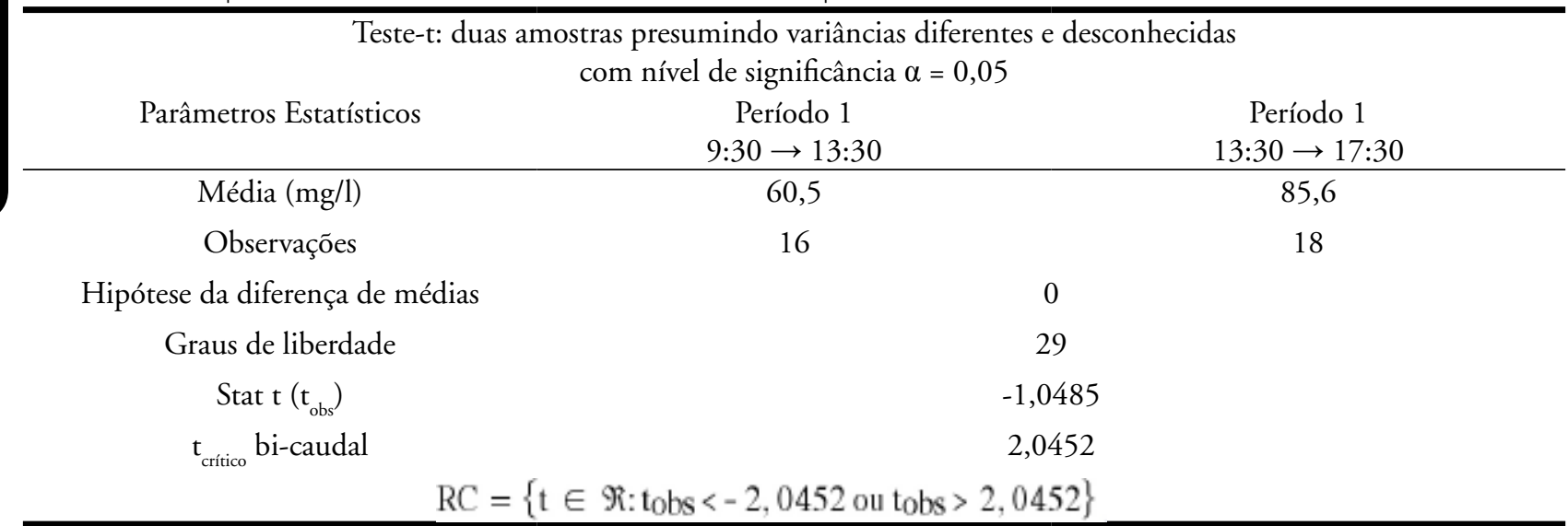

dia; 22 toneladas de areia seca por mês e 264 toneladas de areia seca por ano. Considerando que a massa específica da areia seja igual $2.500 \mathrm{~kg} / \mathrm{m}^{3}$ e que toda a massa de areia apresente índice vazios de cerca de $35 \%$, o volume ocupado por 264 toneladas deste material aproximase de $140 \mathrm{~m}^{3}$ a cada ano.

Ao se considerar o gasto com transporte e disposição final dessa quantidade de areia, caso toda ela seja removida nos desarenadores, o custo de operação e manutenção (O\&M) da ETE pode aumentar consideravelmente. Porém, se tal volume de areia não for devidamente removido em desarenadores devidamente projetados e operados, as conseqüências podem ser: o desgaste excessivo de equipamentos, devido ao contato abrasivo com grãos de areia, e o rápido assoreamento das demais unidades da ETE, que resultaria na diminuição dos tempos de detenção hidráulica (TDH) das unidades de processo e na consequiente queda de eficiência de remoção de matéria orgânica e nutrientes de todo o sistema de tratamento de esgoto sanitário.

\section{CONCLUSÕES}

Com base nos resultados apresentados neste trabalho pode-se concluir que o método desenvolvido para determinar concentração de areia no esgoto sanitário é uma ferramenta interessante e bastante simples, pois além de fornecer resultados satisfatórios, o mesmo é acessível à boa parte dos laboratórios de análise. Vale ressaltar que para determinar a concentração de areia no esgoto sanitário não é necessária a aplicação de toda análise estatística apresentada neste texto, o simples emprego do método analítico desenvolvido fornece subsídios suficientes para melhora do controle operacional e projeto de sistemas de desarenação de ETEs. Constatou-se também que a concentração média de areia no esgoto sanitário afluente da ETE Jardim das Flores, nos períodos estudados, está entre $20 \mathrm{mg} / \mathrm{l} \mathrm{e}$ $73 \mathrm{mg} / \mathrm{l}$, e que os valores de concentração de areia demonstraram grande variabilidade, tanto horária quanto diária. Esta variabilidade não apresentou qualquer padrão significativo de ocorrência.

Por fim, o fato do intervalo de confiança obtido a partir da média aritmética de todos os valores amostrais de concentração de areia ter ficado entre $50 \mathrm{mg} / \mathrm{l} \mathrm{e} 100 \mathrm{mg} / \mathrm{l}$ demonstra a necessidade de olhar mais crítico por parte dos projetistas e operadores de ETEs para as unidades de desarenação, pois o custo agregado à remoção, deságüe e disposição final da areia pode ser significativo no cálculo das despesas operacionais das estaçôes de tratamento. Merece igual destaque o fato de que se esse material não for devidamente removido em desarenadores, o acúmulo de sólidos abrasivos e inertes nas demais unidades das ETEs poderá ocasionar problemas operacionais, diminuição da vida útil de equipamentos e queda na eficiência global de remoção de poluentes de todo o sistema de tratamento.

\section{AGRADECIMENTOS}

Os autores deste trabalho agradecem à CAPES pela bolsa de doutorado concedida, à PROMINAS do Brasil pelo financiamento da pesquisa, ao
DAEE do município de Rio Claro por permitir a realização da pesquisa nas dependências da ETE Jardim das Flores e aos técnicos do LATAR do Departamento de Hidráulica e Saneamento da Escola de Engenharia de São Carlos que colaboraram em todas as etapas do trabalho de pesquisa.

\section{REFERÊNCIAS}

BARROS NETO, B.; SCARMINIO, I. S.; BRUNS, R. E. Como fazer experimentos: pesquisa e desenvolvimento na ciência e na indústria. 2.ed. Campinas, SP: Editora da Unicamp. 2002

CAMP, T. R. Grit chamber design. Sewage Work Journal, v.14, n.2, p.368-381, March. 1942.

GARDNER, P.; DEAMER, A. An evaluation of methods for assessing the removal efficiency of a grit separation device. Water Science and Technology, v.33, n.9, p.269-275. 1996.

METCALF \& EDDY. Wastewater engineering: treatment and reuse. 4.ed. New York: McGraw-Hill, Inc. 2003.

PRADO, G. S. Concep̧̧ão e estudo de uma unidade compacta para tratamento preliminar de esgoto sanitário composta por separador hidrodinâmico por vórtice e grade fina de fluxo tangencial. 240p. Tese (Doutorado) - Escola de Engenharia de São Carlos, Universidade de São Paulo, São Carlos, 2006.

Endereço para correspondência:

\author{
José Roberto Campos \\ Departamento de Hidráulica e \\ Saneamento \\ Escola de Engenharia de São Carlos \\ Universidade de São Paulo \\ Av. Trabalhador São Carlense, $n^{\circ} 400$ \\ Centro \\ I3566-590 - São Carlos - SP - \\ Brasil \\ Tel.: (27) 8808-3 I I 7 \\ E-mail: gustavosprado@gmail.com
}

